ARTIGO

\title{
FORMAÇÃO DE EDUCADORES NA INTERFACE EDUCAÇÃO SUPERIOR - EDUCAÇÃO DO CAMPO: ANÁLISE A PARTIR DA EXPERIÊNCIA NA UNIOESTE
}

\author{
ALEX VERDÉRIO ${ }^{1}$ \\ 0000-0002-0492-6543 \\ JANAINE ZDEBSKI DA SILVA ${ }^{2}$ \\ 0000-0003-0265-0720 \\ JOÃO CARLOS DE CAMPOS ${ }^{3}$ \\ 0000-0002-1928-7377 \\ VALTER DE JESUS LEITE ${ }^{4}$ \\ 0000-0002-3896-1654
}

\begin{abstract}
RESUMO: Analisa o percurso e a efetividade dos cursos de graduação em alternância para formação de educadoras e educadores do campo na Universidade Estadual do Oeste do Paraná (Unioeste), com foco na inserção e permanência dos setores populares na Universidade pública. A elaboração tem como referencial empírico as experiências dos cursos de Pedagogia para Educadores do Campo e Licenciatura em Educação do Campo, concretizadas entre 2004 - 2017 na Unioeste e que promoveram a formação de 137 estudantes. Além das experiências, a análise voltou-se para as Monografias elaboradas nos cursos que, ao tratar de questões da realidade de inserção dos estudantes-pesquisadores evidenciam a relação entre Educação Superior e Educação Básica do Campo a partir da formação de educadores. As experiências formativas analisadas imprimem contribuições na ressignificação da função social da Universidade que incidem no redimensionamento do acesso, do conteúdo e da forma na Educação Superior em sua interface com a Educação do Campo.
\end{abstract}

Palavras-chave: Educação Superior, Educação do Campo, Regime de Alternância, Inclusão de Setores Populares.

\footnotetext{
1 Doutor em Educação. Universidade Federal do Recôncavo da Bahia (UFRB). Amargosa, BA, Brasil. <alexverderio@outlook.com>

${ }^{2}$ Doutora em Ciências Sociais e Humanidades. Universidade Federal do Recôncavo da Bahia (UFRB). Amargosa, BA, Brasil. <janainezs@yahoo.com.br>

3 Doutorando em Educação. Universidade Estadual do Oeste do Paraná (UNIOESTE). Cascavel, PR, Brasil. <jcvncampos@gmail.com>

${ }^{4}$ Doutorando em Educação. Universidade Estadual de Maringá (UEM). Maringá, PR, Brasil. <valterleitemstpr@gmail.com> Educação em Revista|Belo Horizonte |v.37|e229524|2021
} 


\title{
TEACHERS TRAINING IN THE HIGHER EDUCATION INTERFACE - RURAL AREA EDUCATION: ANALYSIS FROM THE UNIOESTE EXPERIENCE
}

\begin{abstract}
It analyzes the route and the effectiveness of the graduation courses in alternation to the rural area teachers training in the Universidade Estadual do Oeste do Paraná (Unioeste), focusing in the insertion and stay of the popular sectors in state universities. The elaboration has as empirical reference the experiences from the Pedagogy courses to the Rural Area Teachers and the Degree in Rural Área Education, finished between 2004-2017 at Unioeste and that promoted 137 student training. In addition to the experiences, the analysis focused on the Monographs made in the courses that when talking about the reality questions of insertion from the students-researchers show the relation between show the relation between Superior and Basic Education from the teachers training. The analyzed formative experiences imprint contributions in the resignification of the University social role that focus on the resizing of the access, content and form in the Superior Education in its interface with the Rural Area Education.
\end{abstract}

Keywords: Superior Education; Rural Area Education; Alternation Regimen; Popular Sectors Inclusion.

\section{FORMACIÓN DE EDUCADORES EN INTERFAZ EDUCACIÓN UNIVERSITARIA - EDUCACIÓN EN CONTEXTOS RURALES: ANÁLISIS DE LA EXPERIENCIA DE LA UNIOESTE}

RESÚMEN: Analiza el curso y la efectividad de carreras de graduación en alternancia para formación de educadores del campo en la Universidad Estatal del Oeste de Paraná (Unioeste), con foco en la inserción y permanencia de sectores populares en la universidad pública. La elaboración tiene como referencial empírico las experiencias de carreras de Pedagogía para Educadores en contextos rurales y Licenciatura en Educación en el Contexto Rural, realizadas entre 2004 - 2017 en la Unioeste y que promovieron la formación de 137 estudiantes. Además de las experiencias, el análisis volcó-se para las monografías elaboradas en estas carreras que, al tratar de cuestiones de la realidad de inserción de los estudiantes-investigadores evidencian la relación entre Educación Universitaria y Educación Básica en contextos rurales a partir de la formación de educadores. Las experiencias formativas analizadas imprimen contribuciones en la resignificación de la función social de la Universidad que inciden en el redimensionamiento del acceso, del contenido y de la forma en la Educación Universitaria en su interfaz con la Educación en Contexto Rural.

Palabras clave: Educación Universitaria; Educación en Contextos Rurales; Régimen de Alternancia; Inclusión de Sectores Populares. 


\section{INTRODUÇÃO}

A Universidade pública no Brasil foi constituída como espaço restrito à formação das elites dirigentes. Essa compreensão é frequentemente afirmada em estudos historicamente situados, mas que mantêm sua atualidade analítica, tais como Álvaro Vieira Pinto (1994) e Marilene Chauí (2001), permitindo-nos verificar elementos que delineiam o papel da Universidade no contexto do Brasil e ao mesmo tempo sublinhar de maneira inequívoca seu caráter eminentemente excludente.

Todavia, nos primeiros anos do século XXI, essa concepção elitista e conservadora da Universidade pública brasileira passou a ser questionada por movimentos agregadores de setores das classes populares que, até então, tinham seu acesso à Educação Superior negado. Tal cenário foi fortalecido, em especial, com os acordos políticos firmados na sociedade brasileira. Assim, nos últimos quinze anos - primeiros do século XXI - a Universidade pública brasileira passou a considerar algumas reivindicações da classe trabalhadora por formação em nível superior. Destacam-se, nesse processo, as cotas para estudantes afrodescendentes e indígenas, bem como a inserção de estudantes oriundos de escolas públicas. Essas ações têm sido perpassadas por inúmeros embates e contradições, mas, por sua vez, produziram importantes mudanças no perfil do estudante universitário brasileiro. Essa reconfiguração tem sido produzida no eco de um conjunto de políticas públicas orientadas para esse fim, conforme ponderam os estudos registrados em Loss et al. (2018) e Loss e Vain (2018).

Dentre as políticas públicas efetivadas com esse objetivo, destacam-se as reivindicadas na luta por uma Educação do Campo. Isso teve seus efeitos também junto à Universidade, o que impulsionou a incorporação e a efetivação de ações endereçadas aos povos trabalhadores do campo, dando corpo e intensificando a interface Educação Superior e Educação do Campo no contexto das Universidades públicas brasileiras. É nesse contexto que a luta por uma Educação do Campo no Brasil, mesmo frente às inúmeras perdas e retrocessos, tem produzido, de modo complementar e recíproco, a ação efetiva no âmbito da conquista de políticas públicas - em todos os níveis e esferas - e a garantia de processos educativos, sempre mediatizados e tensionados na sociedade de classe, mas também relacionados às perspectivas e reivindicações dos povos trabalhadores do campo em luta. Esse processo é sustentado e é sustentador da ação protagonizada pelos povos trabalhadores do campo, sobretudo, por meio de suas organizações sociais. Neste quadro,

[...] compreende-se como luta por uma Educação do Campo a articulação de diversos sujeitos comprometidos com a educação dos povos trabalhadores do campo no Brasil, tendo como elemento central os sujeitos a que se refere como protagonistas na proposição e na realização de uma educação que atenda seus interesses e, estando conectada a processos educacionais contra-hegemônicos, se coloca na perspectiva da transformação social e da emancipação humana.

Assim, a luta por uma Educação do Campo parte da própria diversidade dos sujeitos trabalhadores do campo no Brasil e das práticas e perspectivas educativas forjadas nas lutas sociais de tais sujeitos. A luta por uma Educação do Campo se faz diversa na unidade de classe. Não é homogênea e nem uniforme, mas possui uma materialidade de origem que a identifica e lhe confere unidade (VERDÉRIO, 2018, p. 66-67).

O cenário contraditório e imerso em contínuos embates instiga a refletir e analisar processos realizados na controvérsia entre conquistas e retrocessos, rupturas e conservadorismos, onde, na Universidade pública, ao mesmo tempo, coloca-se o velho e o novo, sendo ela tensionada cotidianamente, no contexto da luta de classes. Se por um lado a Universidade pública é contingenciada a expandir sua capilaridade e a possibilidade de inserção de sujeitos diversos que até então não a frequentavam, ao mesmo tempo, ela vê-se eivada pelos padrões autoritários, oligárquicos e violentos da sociedade brasileira e capitalista em geral (CHAUÍ, 2001).

No contexto de impulsionar estudos e pesquisas que analisem qualitativamente essa inserção, colocou-se o Programa de Desenvolvimento Acadêmico Abdias Nascimento, vinculado ao Edital SECADI/CAPES No 02/2014, como uma possibilidade concreta de analisar e sistematizar elementos acerca da inclusão e permanência de Setores Populares no Ensino Superior. Com a perspectiva investigativa assumida na pesquisa, consideradas as ações de inserção e permanência desenvolvidas pela Unioeste, sobretudo entre os anos de 2004 e 2017, optou-se por uma análise voltada para as ações 
efetivadas na interface Educação Superior e Educação do Campo, que sustentada na parceria com os Movimentos Sociais Populares do Campo, trouxe para dentro da Universidade pública, uma parcela da sociedade brasileira que, até pouco tempo, não possuía como perspectiva o acesso à Educação Superior.

Desse modo, em consonância com a proposta de pesquisa vinculada ao Programa Abdias Nascimento, foi constituído o Eixo de Pesquisa Educação do Campo voltado para a análise da formação de educadores do campo na Unioeste em parceria com os Movimentos Sociais Populares do Campo.

Dentre os procedimentos metodológicos, além da vinculação orgânica com os processos formativos analisados, destacaram-se a pesquisa documental e a pesquisa bibliográfica.

Como referenciais empíricos primeiros, foram considerados o Programa Nacional de Educação na Reforma Agrária (PRONERA) e o Programa de Apoio à Licenciatura em Educação do Campo (PROCAMPO) em sua efetividade junto à Unioeste, o que permitiu concretizar a formação de educadores do campo em cursos de nível superior, organizados em regime de alternância. A análise desses dois Programas - PRONERA e PROCAMPO - e de algumas de suas ações que, dentre outras, constituem a política pública de Educação do Campo no Brasil, teve como chave de análise a compreensão produzida coletivamente na própria luta por uma Educação do Campo, a qual entende que é a partir da luta organizada dos trabalhadores do campo que o Estado, por meio das políticas públicas, responde às demandas protagonizadas por diferentes setores sociais frente às suas reinvindicações. Dessa forma, as políticas públicas colocam-se como ações mediatizadas e tensionadas continuamente, ora pautadas pela orientação hegemônica do Estado, ora pautadas pelas lutas dos trabalhadores, no caso aqui posto, os povos trabalhadores do campo e suas organizações.

A partir dos dados produzidos e da análise sobre a efetividade do PRONERA e do PROCAMPO, foi analisado o perfil do público que se inseriu na Educação Superior na Unioeste por meio dos cursos de Pedagogia para Educadores do Campo e de Licenciatura em Educação do Campo. Para tanto, foi elaborado um mapeamento dos sujeitos que constituíram as quatro turmas dos dois cursos na Universidade. Como referenciais empíricos da pesquisa foram assumidos: os Memoriais de Vida elaborados nos processos de seleção das turmas, os Trabalhos de Conclusão de Curso e os documentos pertinentes aos cursos arquivados na Universidade.

A partir da produção dos dados de pesquisa e com a análise do perfil do público constituinte de cada turma dos cursos de graduação em Educação do Campo na Unioeste foi possível, ainda, construir um perfil acerca da produção acadêmico-científica dos envolvidos. Nestes termos, colocou-se como elemento central de análise e compreensão o entendimento de que o vínculo com a Educação Superior na interface com a Educação do Campo no contexto da Unioeste teve por referência de inserção e permanência a vinculação aos Movimentos Sociais Populares do Campo. Essa chave de leitura e compreensão foi evidenciada a partir da análise dos 137 Trabalhos de Conclusão de Curso produzidos no curso de Pedagogia para Educadores do Campo e no curso de Licenciatura em Educação do Campo na Unioeste.

Os dados produzidos, em seu conjunto, permitiram pontuar ainda que a inserção na graduação, por meio da efetividade de políticas públicas afirmativas e de inclusão, abre o leque de possibilidades para reflexão prático-teórica acerca das ações de educação desenvolvidas no âmbito dos Movimentos Sociais Populares do Campo e da Educação Básica do Campo traduzida, dentre outros, na elaboração dos Trabalhos de Conclusão de Curso.

\section{A FORMAÇÃO DE EDUCADORES DO CAMPO E A AFIRMAÇÃO DA POLÍTICA PÚBLICA DE EDUCAÇÃO DO CAMPO: O PRONERA E O PROCAMPO}

A política pública de Educação do Campo tem sido constituída pelo Estado brasileiro como resultado da luta, da organização e da mobilização dos povos trabalhadores do campo na perspectiva da garantia de seu direito à educação. Neste quadro, dois Programas Governamentais voltados para a Educação do Campo em sua interface com a Educação Superior ganham destaque: o PRONERA e o PROCAMPO. 
O PRONERA foi instituído em 16 de abril de 1998, por meio da Portaria n ${ }^{\circ} 10$, do extinto Ministério Extraordinário da Política Fundiária (SANTOS, 2012), sendo apresentado à sociedade brasileira na I Conferência Nacional de Educação do Campo, ocorrida também em 1998. Destaca-se que:

O período inicial da experiência, entre 1998-2002, é marcado por um intenso conflito, uma vez que o Estado Nacional e a sua política de Estado-Mínimo se contrapunham a iniciativas populares como a que está em análise. É interessante observar essa contradição, pois é justamente no momento de maior intensidade no combate aos movimentos sociais, e de escassez de políticas públicas ao conjunto da população que se avança para uma iniciativa de política pública popular (GHEDINI et al., 2018, p. 265-266).

A partir desse contexto, o PRONERA coloca-se no sentido de:

Fortalecer a educação nas áreas de Reforma Agrária estimulando, propondo, criando, desenvolvendo e coordenando projetos educacionais, utilizando metodologias voltadas para a especificidade do campo, tendo em vista contribuir para a promoção da inclusão social com desenvolvimento sustentável nos Projetos de Assentamento de Reforma Agrária (BRASIL, 2016, p. 18).

O PRONERA é um marco na construção da Educação do Campo no Brasil, também no âmbito da política pública. Sua efetividade o coloca na condição de "[...] primeira ação de envergadura do Estado brasileiro na perspectiva de constituir uma resposta enfática à luta por uma Educação do Campo, ele demarca uma nova apreensão acerca da ação governamental na relação direta com as reivindicações sociais.” (VERDÉRIO, 2018, p. 96).

Dentre as inovações introduzidas pelo PRONERA, destaca-se o modelo de gestão tripartite, que conta com a participação de membros do governo federal, de universidade e movimentos sociais [...]. As instituições de ensino superior cumprem a função estratégica no Programa, pois acumulam papéis de mediação entre os movimentos sociais e o Instituto de Colonização e Reforma Agrária (INCRA), de gestão administrativo-financeira e coordenação pedagógica dos projetos. Os movimentos sociais respondem pela mobilização das comunidades, enquanto as Superintendências Regionais do Incra (SRs) desempenham funções de acompanhamento financeiro, apoio logístico e articulação interinstitucional. Em tese, as secretarias estaduais e municipais de Educação deveriam apoiar a implantação dos projetos, assegurando sua continuidade, o que raramente acontece (ANDRADE; DI PIERRO, 2004, p. 22-23).

O Decreto Presidencial no 7.352 , de 04 de novembro de 2010, por sua vez, instituiu o PRONERA como ação integrante da política pública de Educação do Campo. Conforme informações coletadas na página oficial do Instituto Nacional de Colonização e Reforma Agrária (INCRA), em dezoito anos de existência, o PRONERA viabilizou a formação de mais de 185 mil jovens e adultos beneficiários do Programa Nacional de Reforma Agrária (INCRA, 2016). Além dos beneficiários diretos do Programa Nacional de Reforma Agrária, dentre os possíveis atendidos pelo PRONERA, também estão:

Professores e educadores, com vínculo efetivo ou temporário com as Secretarias Municipais e/ou Estaduais de Educação, que exerçam atividades educacionais em atendimento direto às famílias beneficiárias, nas escolas localizadas nos assentamentos ou no entorno, que atendam à comunidade assentada, o que deverá ser comprovado por meio de documento emitido por um destes órgãos. (BRASIL, 2016, p. 21).

Na sequência, o Mapa 1 apresenta um panorama que permite dimensionar a abrangência do PRONERA em nível nacional com os cursos de graduação em regime de alternância realizados entre 1998 e 2011.

Mapa 1: Cursos em nível superior ofertados pelo PRONERA (1998-2011) 

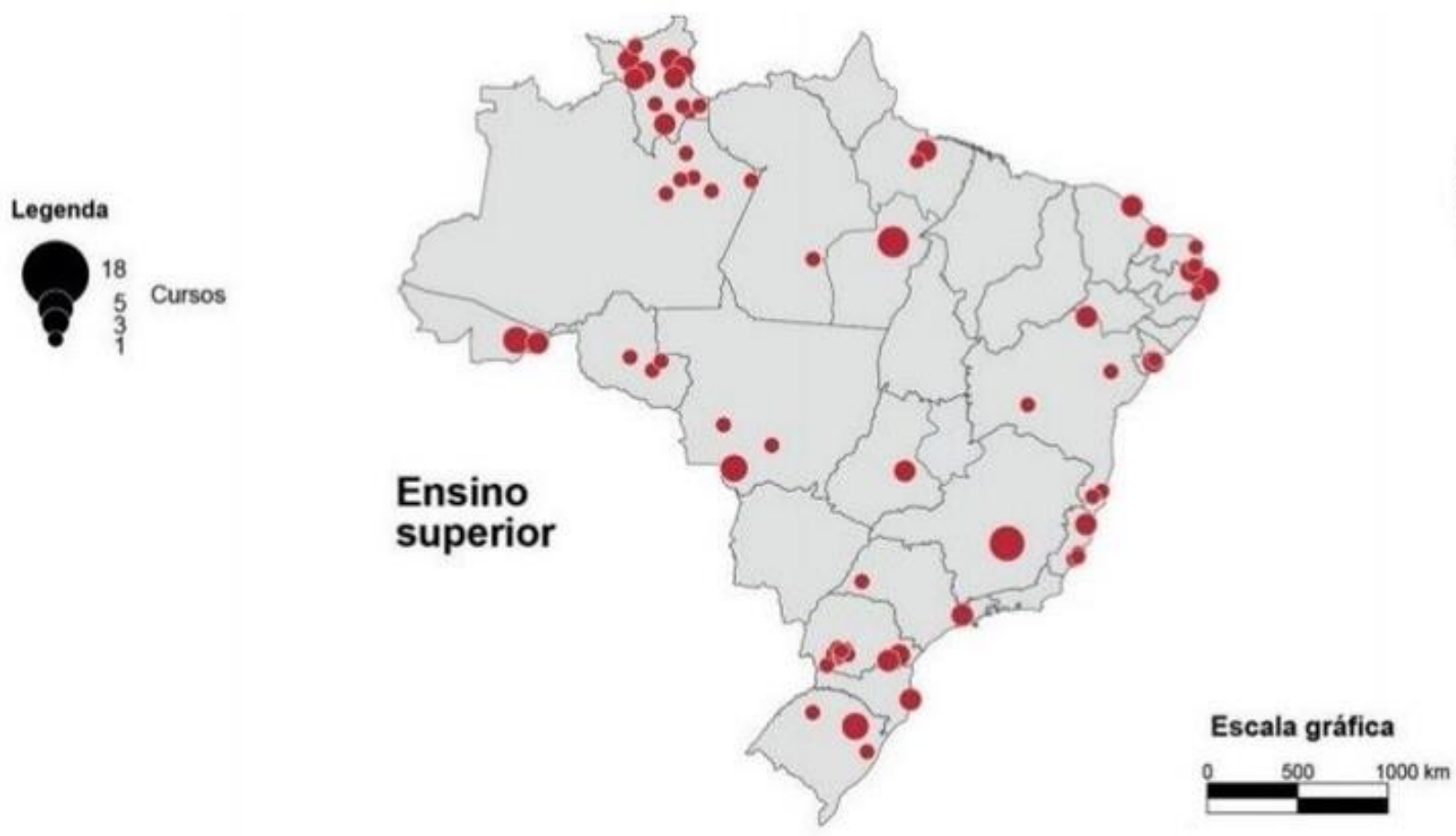

FONTE: adequação a partir de IPEA (2015).

O panorama apresentado no Mapa 1, ao mesmo tempo em que expressa ações concretas de acesso e permanência de setores populares à Universidade pública no Brasil, registra também a condição do PRONERA como impulsionador da interface Educação Superior e Educação do Campo. Essa condição incide no próprio delineamento e na capilaridade da política pública de Educação do Campo no território nacional, sobretudo, com os cursos de graduação para formação de educadores do campo em regime de alternância, dentre os quais está o curso de Pedagogia para Educadores do Campo, que foi ofertado pela Unioeste na parceria constituída com os Movimentos Sociais Populares do Campo e o próprio PRONERA.

De acordo com dados da II Pesquisa Nacional sobre a Educação na Reforma Agrária (IPEA, 2015), entre os anos de 1998 e 2011, foram realizados 320 cursos por meio do PRONERA, sendo 167 cursos de Educação de Jovens e Adultos - Ensino Fundamental, 99 cursos de Ensino Médio e $\mathbf{5 4}$ cursos em nível superior.

Horácio (2015), por sua vez, registra que entre 1998 e 2014 ocorreram dezenove turmas do curso de Pedagogia da Terra em alternância no Brasil. As turmas foram efetivadas por meio do PRONERA, envolvendo doze Universidades públicas. Esse dado permite verificar a formação de educadores do campo em cursos de graduação em regime de alternância como uma conquista da luta por uma Educação do Campo e que foi impulsionada pelo PRONERA a partir de 1998.

Assim como o PRONERA, a partir de 2008, o PROCAMPO assumiu a condição de ação fundamental do Governo Federal na promoção e realização da formação de educadores do campo no Brasil, culminando com a efetivação do curso de Licenciatura em Educação do Campo em Universidades Estaduais, Federais e Institutos de Educação Superior.

De acordo com Ramos et al. (2004, p. 5), a proposição do curso de Licenciatura em Educação do Campo e a formulação do PROCAMPO se processaram inicialmente no interior do Grupo Permanente de Trabalho em Educação do Campo, "[...] instituído no âmbito do MEC, pela Portaria ${ }^{\circ}$ 1.374 de 03/06/03, com a atribuição de articular as ações do Ministério pertinentes à Educação do Campo [...]". Um dos resultados da atuação desse Grupo Permanente foi a formulação da minuta original 
do curso de Licenciatura (Plena) em Educação do Campo (MEC, 2006), que posteriormente sustentou a realização das quatro primeiras experiências-piloto ${ }^{5}$ do curso no Brasil.

A partir da realização das experiências-piloto, em 2008, o MEC, por meio da Secretaria de Educação Continuada, Alfabetização, Diversidade e Inclusão (SECADI), publicou o primeiro edital para implementação do curso de Licenciatura em Educação do Campo nas Universidades que se propunham a apresentar propostas. Com o primeiro edital do PROCAMPO, foram selecionadas 27 propostas para realização do curso em quatorze estados da federação mais o Distrito Federal (BRASIL, 2008). Dentre as propostas aprovadas pelo edital PROCAMPO de 2008, estava a proposta apresentada pela Unioeste campus Cascavel.

Em abril de 2009, o MEC publica o Edital de Convocação no 09, constituindo assim o segundo edital do PROCAMPO. Considerando os cursos aprovados pelo edital de 2008, somados aos cursos aprovados pelo edital de 2009, o MEC divulgou a participação de 33 Instituições de Educação Superior no PROCAMPO até 2010. De acordo com Brasil (2010), a efetivação dos dois editais promoveu a constituição de 56 turmas do curso e um total de 3.358 vagas disponibilizadas para formação de educadores do campo no curso de Licenciatura em Educação do Campo, em alternância e por áreas do conhecimento.

Em março de 2012, o PROCAMPO passou a integrar o Programa Nacional de Educação do Campo (PRONACAMPO). No âmbito da ação do MEC, o PRONACAMPO, proposto e gerido pela SECADI, colocou-se como "[...] um conjunto articulado de ações de apoio aos sistemas de ensino para

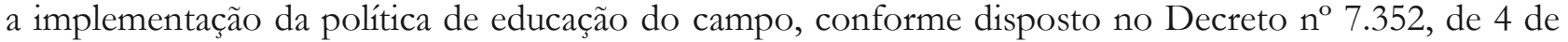
novembro de 2010" (BRASIL, 2013, p. 1). Com a instituição do PRONACAMPO, no âmbito da formação de educadores do campo em cursos de graduação, dentre outras, foram reafirmados os dois elementos estruturantes dos cursos de Licenciaturas em Educação do Campo no Brasil: a organização em regime de alternância e a formação por áreas do conhecimento.

De acordo com informações organizadas por Verdério (2018), a partir da Portaria $\mathrm{n}^{\circ} 72$, de 21 de dezembro de 2012 que divulgou o resultado da terceira seleção de propostas apresentadas ao PROCAMPO, verifica-se que o terceiro edital contemplou um conjunto de 44 Universidades Federais, distribuídas em dezenove estados brasileiros mais o Distrito Federal.

De acordo com o Mapa 2, constata-se que com o terceiro edital do PROCAMPO foi produzido um significativo aumento quanto à oferta de vagas e implementação do curso de Licenciatura em Educação do Campo no Brasil. Esse significativo aumento teve relação direta com a possibilidade posta pelo terceiro edital do PROCAMPO, que assegurou às Universidades Federais que aderissem ao edital a contratação de quinze professores efetivos e três técnicos administrativos, juntamente com um custeio inicial de R \$ 4.000,00 estudante/ano. Essa disposição do MEC em disponibilizar a contratação de professores e de técnicos educacionais por meio de concurso público, mais os recursos de custeio inicial para constituição das turmas impulsionaram o PROCAMPO e a expansão do curso de Licenciatura do Campo como ação prioritária do MEC junto às Universidades Federais.

\section{Mapa 2: Territorialização dos cursos de licenciatura em Educação do Campo, Brasil}

\footnotetext{
${ }^{5}$ As experiências foram realizadas a partir de convite do MEC direcionado a quatro Universidades Federais, sejam elas: a Universidade de Brasília (UnB), a Universidade Federal de Minas Gerais (UFMG), a Universidade Federal da Bahia (UFBA) e a Universidade Federal de Sergipe (UFS). Essa ação, de acordo com Molina e Sá (2011), permitiu e resultou na própria configuração do PROCAMPO. 


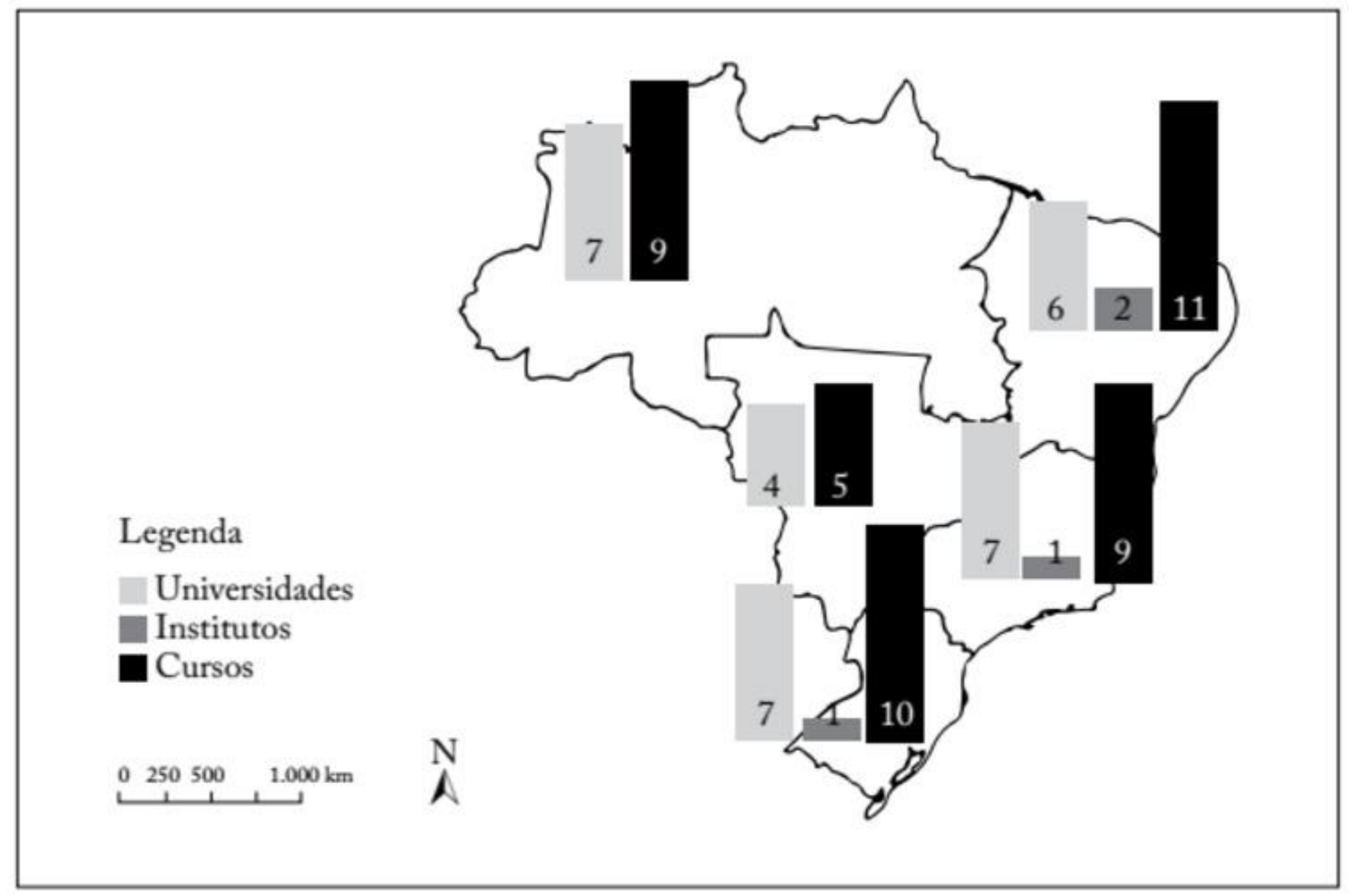

FONTE: Leal et al. (2019, p. 47).

De acordo com Molina et al. (2019, p. 10) e conforme expresso no Mapa 2, verificam-se 44 cursos de Licenciatura em Educação do Campo em andamento no Brasil, distribuídos em 31 Universidades e em quatro Institutos Federais de Educação. Ainda de acordo com dados sistematizados por Verdério (2018), até 2018, quando consideradas todas as Universidades (Estaduais e Federais), Institutos Federais de Educação e outras Instituições de Educação Superior que se envolveram com o PROCAMPO, chega-se a um total de 53 Instituições de Educação Superior no Brasil que desenvolveram ou desenvolviam experiências com o curso de Licenciatura em Educação do Campo, organizadas em áreas de conhecimento e realizadas no regime de alternância.

\section{A UNIOESTE E A FORMAÇÃO DE EDUCADORES DO CAMPO: PEDAGOGIA PARA EDUCADORES DO CAMPO E LICENCIATURA EM EDUCAÇÃO DO CAMPO}

No Paraná a demanda por cursos de graduação em regime de alternância tem sua expressão mais elaborada a partir da atuação da Articulação Paranaense por uma Educação do Campo (APEC). Foi na II Conferência Estadual de Educação do Campo, ocorrida em novembro de 2000, no município de Porto Barreiro - PR, que tal reivindicação tomou fôlego e alcançou eco junto às Instituições Públicas de Educação Superior do estado.

$\mathrm{Na}$ Carta de Porto Barreiro foi registrada a reinvindicação de "Criação do curso de Pedagogia da Terra no Estado do Paraná" (APEC, 2000, p. 56). Essa necessidade já vinha sendo apontada pelo MST desde a instituição do PRONERA, em 1998. Contudo, foi a realização da II Conferência Estadual que impulsionou tal demanda, colocando-a na ordem do dia da luta por uma Educação do Campo no Paraná. Dentre os diversos promotores da II Conferência estava a Unioeste, essa condição da Universidade colocou-a em posição favorável para a construção do curso.

A projeção inicial de um curso de graduação em alternância para formação de educadores do campo no interior da Unioeste, além da reivindicação dos povos trabalhadores do campo, ganhou 
fôlego durante o processo de greve desencadeado pelos servidores das Universidades Estaduais do Paraná, no início da década de 2000.

Entre os anos de 2001 e 2002 as universidades paranaenses enfrentam um longo período de greve. Em meio a este processo, um grupo de servidores da UNIOESTE se envolveu com o debate em torno do papel social da universidade, especialmente na região onde está situada, debate este que culminou com a indicação de um seminário para discutir a questão agrária. Com a realização desse evento sai a proposição de que a elaboração de um projeto para a formação de educadores do campo deveria ser prioridade (UNIOESTE, 2006, p. 02).

A reivindicação dos povos trabalhadores do campo - expressa na Carta de Porto Barreiro em conexão direta com a disposição interna da Unioeste - propiciada por sua participação na II Conferência e pelo movimento de greve que intensificou o debate acerca da função social da Universidade - juntamente à efetividade do PRONERA produziram as condições objetivas iniciais para a gestação do curso de Pedagogia para Educadores do Campo. Posteriormente, esses elementos iniciais mais a experiência acumulada pela Unioeste no curso de Pedagogia da Terra colocaram-se como fundamentais para a proposição na Universidade do curso de Licenciatura em Educação do Campo no âmbito do PROCAMPO.

A Unioeste é uma Universidade pública estadual de caráter multicampi que tem sua abrangência distribuída nas regiões Oeste e Sudoeste do Paraná, consolidada na existência de cinco campi localizados nos municípios de Cascavel, Foz do Iguaçu, Francisco Beltrão, Marechal Cândido Rondon e Toledo.

Como instituição pública estadual de Educação Superior, a Unioeste foi constituída em 1994 a partir "[...] da congregação de faculdades municipais isoladas, criadas em Cascavel (FECIVEL, 1972), em Foz do Iguaçu (FACISA, 1979), em Marechal Candido Rondon (FACIMAR, 1980) e em Toledo (FACITOL, 1980).” (UNIOESTE, 2017). Em 1998, com a incorporação da FACIBEL, localizada no município de Francisco Beltrão, é instituído seu quinto campus universitário. De acordo com informações apresentadas na página oficial da instituição (UNIOESTE, 2017), ela abrange 94 municípios, 52 destes localizados na região Oeste e 42 na região Sudoeste do Paraná.

De acordo com informações disponíveis nos Boletins de Dados (UNIOESTE, 2019), verifica-se que no período entre 2004 e 2017, a Universidade ofertou quatro turmas de graduação para formação de educadores do campo em alternância, três delas vinculadas ao PRONERA e uma ao PROCAMPO. Quando considerados os dados pertinentes ao campus de Francisco Beltrão, que ofertou a primeira turma do curso de Pedagogia para Educadores do Campo entre 2004 e 2008, constata-se que no ano letivo de 2007, das 560 matrículas pertinentes aos cursos de licenciatura naquele campus, 36 delas estavam vinculadas ao curso de Pedagogia para Educadores do Campo, iniciado em 2004. Esse montante de 36 matrículas condiz a 6,4\% das matrículas nos cursos de licenciatura do campus de Francisco Beltrão em 2007.

Em 2009, quando o curso de Pedagogia para Educadores do Campo foi transferido para o campus de Cascavel e quando é firmado o convênio com o PROCAMPO para a realização de uma turma do curso de Licenciatura em Educação do Campo, verifica-se que fica ainda mais evidente a formação de educadores do campo na Unioeste. Com isso, como expresso no Gráfico 1, constata-se uma incidência no número de matrículas no conjunto dos cursos de licenciatura ofertados no campus da Universidade em Cascavel.

Gráfico 1: Matrículas nos cursos de Licenciatura Unioeste campus de Cascavel 2009- 2017 


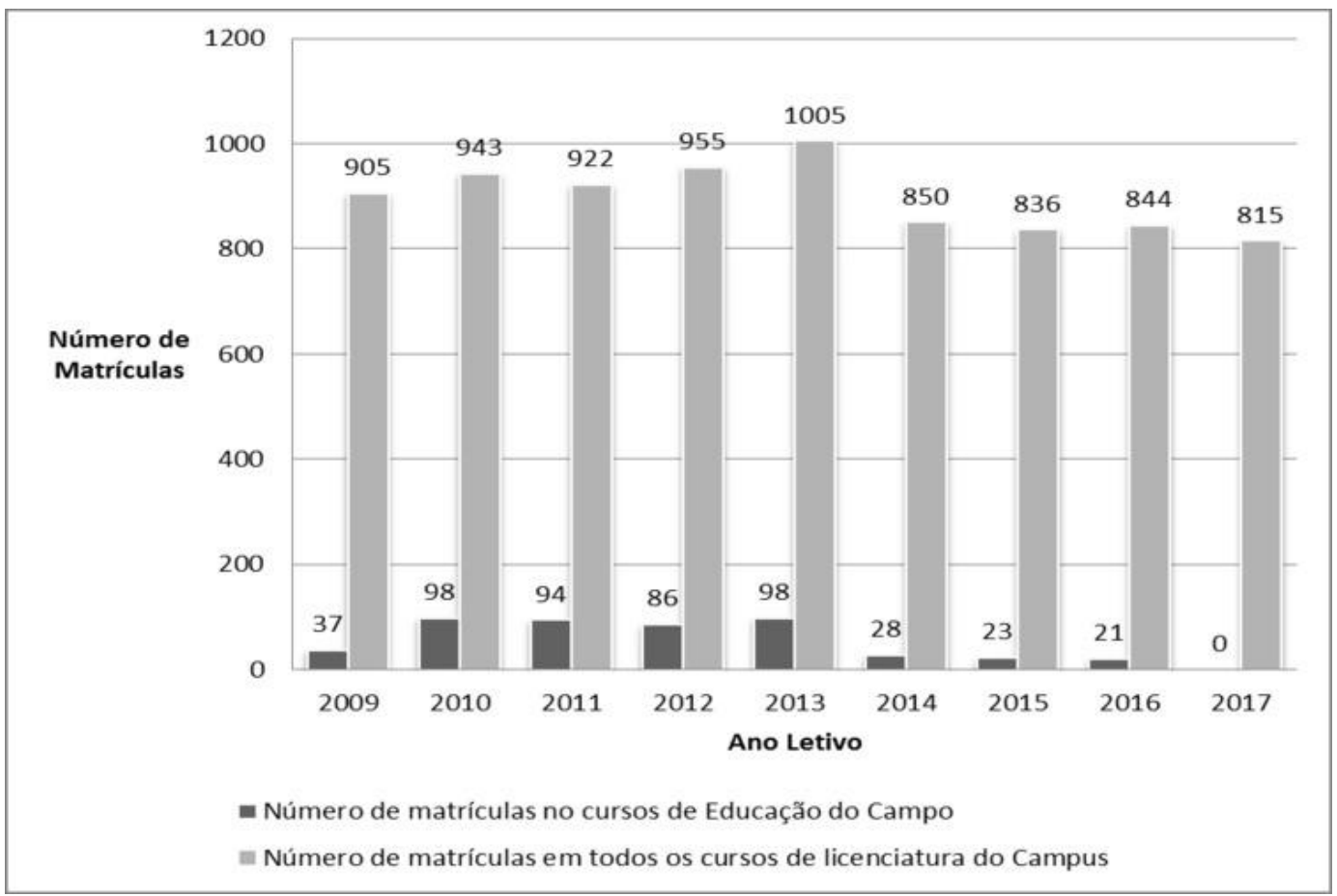

FONTE: Organização dos autores (2019).

Conforme informações sintetizadas no Gráfico 1, pontua-se que a realização do cursos de Pedagogia para Educadores do Campo e de Licenciatura em Educação do Campo na Unioeste campus de Cascavel passaram a ser fator fundamental para a inserção de setores populares na Educação Superior, em especial dos povos trabalhadores do campo. Destaca-se ainda que essas ações constituíram-se como elemento de importante representatividade no que se refere ao percentual de matrículas no conjunto de cursos de licenciatura ofertados pela Universidade no campus de Cascavel, que passou a oferecer de forma concomitante os dois cursos de formação de educadores do campo em regime de alternância efetivados na Unioeste.

Ainda de acordo com a síntese disposta no Gráfico 1, destaca-se que o ápice da inserção e da incidência dos cursos de formação de educadores do campo em alternância na Unioeste se deu nos anos letivos de 2010 e 2011, com a concomitante efetivação do curso de Pedagogia para Educadores do Campo - PRONERA - e do curso de Licenciatura em Educação do Campo - PROCAMPO. Em 2010, as 98 matrículas pertinentes aos dois cursos representaram 10,4\% do total de matrículas nos cursos de licenciatura do campus. Em 2011, as 94 matrículas em ambos os cursos compuseram 10,2\% do total de matrículas nos cursos de licenciatura do campus. Destaca-se ainda, que, dos nove cursos ofertados nos referidos anos, dois eram de Educação do Campo e em alternância, ofertados em turmas específicas, realizadas no formato de experimento pedagógico e como resultados do delineamento da política pública de Educação do Campo.

Os cursos de Pedagogia para Educadores do Campo e de Licenciatura em Educação do Campo, dentre outras ações, registram o protagonismo e o pioneirismo da Unioeste juntamente com os Movimentos Sociais Populares do Campo na interface Educação Superior e Educação do Campo e na oferta de cursos em alternância no Paraná, possibilitando a inserção de uma parcela dos setores populares que até então não tinham acesso à Educação Superior.

Como registrado anteriormente, a primeira turma do curso de Pedagogia para Educadores do Campo na Unioeste, organizada sob o regime de alternância, ocorreu entre os anos de 2004 e 2008, 
no campus de Francisco Beltrão. Essa que foi a primeira turma do curso de Pedagogia da Terra no Paraná foi identificada pelos estudantes que a compuseram como Turma Antonio Gramsci ${ }^{6}$.

De acordo com o Projeto Político-Pedagógico (PPP) do curso (UNIOESTE, 2004 e 2013), a Pedagogia para Educadores do Campo na Unioeste, nas três turmas efetivadas, objetivou a formação de educadores para atuar nos anos iniciais do Ensino Fundamental, na Educação Infantil e na Educação de Jovens e Adultos.

Como expresso anteriormente, a luta pela criação deste primeiro curso em alternância no Paraná tem sua origem na II Conferência Estadual por uma Educação do Campo, realizada em 2000. O parecer favorável do Conselho Pedagógico do PRONERA para a criação do curso se deu em 13 de outubro de 2003. Em 28 de outubro do mesmo ano, a Unioeste, por meio da Resolução no 145/2003 do seu Conselho de Ensino, Pesquisa e Extensão (CEPE), aprovou o PPP do curso de Pedagogia para Educadores do Campo, na modalidade de Licenciatura, em regime especial, estando o mesmo vinculado ao Centro de Ciências Humanas $(\mathrm{CCH})$ do campus de Francisco Beltrão e viabilizado pelo convênio com o PRONERA. O curso teve seu início previsto para o ano letivo de 2004. Com as Resoluções $\mathrm{n}^{\circ}$ 090/2003-COU e 091/2003-COU de 30 de outubro de 2003, o Conselho Universitário (COU) da Unioeste aprovou o impacto financeiro e sancionou a criação do curso.

Após a aprovação em suas instâncias internas, a Universidade solicitou autorização de funcionamento do curso à Secretaria de Ciência, Tecnologia e Ensino Superior (SETI). Com isso, em 05 de dezembro de 2003, a SETI, por meio do Ofício no 750 , encaminhou ao Conselho Estadual de Educação do Estado (CEE) do Paraná, para análise e parecer. A Comissão verificadora instituída pelo CEE em 03 de março de 2004, pela Portaria no 04 daquele ano, emitiu parecer favorável à realização do curso em maio de 2004. A visita da Comissão do CEE à Unioeste foi realizada em 22 de março de 2004. Em seu relatório, a Comissão indicou adequações ao PPP e a necessidade de providenciar algumas condições estruturais para a execução do curso, destacando a necessidade de aquisição de acervo voltado às bibliografias presentes no PPP do curso.

No dia 07 de maio de 2004, a partir de voto favorável da relatora autorizando o funcionamento do curso como experimento pedagógico, a Câmara de Educação Superior do CEE aprovou por unanimidade o voto da relatora, seguido da aprovação também por unanimidade pelo Plenário do CEE. Com a autorização de funcionamento do curso, a Unioeste, por meio da Resolução $n^{\circ}$ 076/2004-CEPE, de 18 de maio de 2004, estabeleceu procedimentos relativos ao funcionamento do curso quanto ao calendário, aos docentes, aos planos de ensino dos componentes curriculares e sobre os sujeitos que poderiam participar do processo seletivo do curso.

Como parte constituinte de seu Parecer, o CEE indicou à Unioeste a criação de um Grupo de Trabalho, sendo o mesmo instituído pela Universidade por meio da Resolução no 077/2004-CEPE, de 18 de maio 2004. Além de contar com representantes da Universidade, o referido Grupo de Trabalho contou com a participação de representação do município de Francisco Beltrão e do Governo Estadual do Paraná, da Comissão Regional de Atingidos por Barragens do Rio Iguaçu (CRABI), da Associação de Estudos Orientação e Assistência Rural (ASSESOAR) e do MST. O Grupo de Trabalho constituído teve por tarefa central acompanhar a implementação do curso.

No mês de junho de 2004 foi realizada a etapa preparatória para o processo de seleção para constituição do curso na sede da ASSESOAR em Francisco Beltrão. Já o Concurso Vestibular Específico para constituição da turma ocorreu nos dias 24 e 25 do mesmo mês na Unioeste, campus de Francisco Beltrão. O processo de seleção contou com a elaboração de uma redação - na forma de Memorial de Vida - e a resolução de dez questões de Língua Portuguesa, dez questões de Matemática e cinco questões nas disciplinas de História, Geografia, Física, Química, Biologia e Língua Espanhola. O Concurso Vestibular teve 55 candidatos inscritos e desses, 53 compareceram nos dias das provas. Com a publicação do edital no 011/2004, em 30 de junho, que divulgou o resultado do Concurso Vestibular, ocorreram seis reprovações.

\footnotetext{
${ }^{6}$ Antonio Gramsci $(1891$ - 1937). Pensador italiano. Membro do Partido Comunista da Itália. Preso pelo Regime Facista. Foi homenageado como nome de turma pela primeira turma do curso de Pedagogia para Educadores do Campo na Unioeste. Educação em Revista|Belo Horizonte|v.37|e229524|2021
} 
As atividades acadêmicas do curso de Pedagogia para Educadores do Campo na Unioeste iniciaram em agosto de 2004 com 46 estudantes matriculados, uma perda, já que se considerava uma demanda de aproximadamente quinhentos educadores que necessitavam de formação nos distintos municípios do Paraná. O curso atenderia $10 \%$ da demanda total estimada nesta primeira edição (UNIOESTE, 2004, p. 6), contudo, foi iniciado com quatro vagas ociosas.

As características do curso, por estar organizado em regime de alternância entre tempo universidade e tempo comunidade, tinha como possibilidade o custeio público da estadia, alimentação e deslocamento através do PRONERA. Com essa disposição de recursos, o curso proporcionou o acesso de uma heterogeneidade de sujeitos das distintas regiões do Paraná, uma estudante vinda do estado de São Paulo, três estudantes do estado de Santa Catarina e um do estado do Rio Grande do Sul. A turma foi composta por sujeitos vindos de 26 comunidades camponesas, vinculadas ao Movimento de Atingidos por Barragens (MAB), à CRABI, ao MST, à ASSESOAR e às Casas Familiares Rurais (CFR's).

Ao longo dos quatro anos de curso, ocorreram doze desistências, pelos mais variados motivos, perpassados pelo desinteresse com a área de atuação, a problemas pessoais e econômicos que impossibilitaram a continuidade nos estudos. Houve também uma transferência que viabilizou a inserção de uma estudante no curso. Portanto, concluíram a formação propiciada na primeira turma do curso de Pedagogia para Educadores do Campo na Unioeste 35 estudantes, 21 mulheres e quatorze homens.

A partir da análise dos dados referentes ao local de moradia dos estudantes, verificada nos Memoriais de Vida, no início do curso e os vínculos com os Movimentos Sociais, constata-se que a maioria dos estudantes concluintes da Turma Antonio Gramsci tinham sua inserção em Acampamentos e Assentamentos organizados pelo MST, totalizando 28 estudantes com tal vínculo. Considerando o conjunto da turma egressa em 2008, quinze estudantes residiam em Acampamentos de luta pela terra, onze em Assentamentos da Reforma Agrária, duas em áreas de Reassentamento de Comunidades Atingidas por Barragens, duas ligadas às CFR's, quatro residiam em Comunidades Camponesas da Agricultura Familiar e uma pessoa não foi possível identificar o local de residência.

Analisando o PPP da primeira turma do curso de Pedagogia para Educadores do Campo na Unioeste, a Turma Antônio Gramsci, ao tratar das finalidades do curso, identifica-se que a construção desse curso se constituiu em uma nova experiência, com identidade própria, "com uma nova forma de organização", singularidade que se afirma na diferenciação de seus próprios sujeitos (UNIOESTE, 2004, p. 11). Essa especificidade dos sujeitos é afirmada já no processo de acesso ao curso, pois cada estudante, para ingressar no curso, além de participar e ser aprovado no Concurso Vestibular Específico, necessitou de uma indicação de sua Comunidade ou Movimento Social - a Carta de Indicação a ser apresentada à Coordenação do curso. A partir desse critério, os estudantes que constituíram a Turma Antonio Gramsci tiveram na sua própria inserção nas Comunidades do Campo um dos elementos que lhes possibilitaram a inserção no curso. Isso implicou e intensificou o engajamento político-pedagógico na construção do curso, vinculando-o a um projeto de campo e de sociedade. Essa disposição em reafirmar continuamente a inserção nas Comunidades do Campo constituiu-se como um dos eixos do processo formativo desencadeado, estando atrelado intrinsecamente à estruturação do curso sob o regime de alternância entre tempo universidade e tempo comunidade.

Dessa maneira, desde o início do curso, os estudantes que constituíram a Pedagogia da Terra Turma Antonio Gramsci mantiveram vínculos orgânicos com os Movimentos Sociais, Organizações Comunitárias e Comunidades do Campo, potencializando sua inserção no curso e na Comunidade a partir da participação efetiva em processos educativos, seja na educação formal como é o caso das Escolas Itinerantes ${ }^{7}$, dos Cursos Técnicos em Centros de Formação em Agroecologia ${ }^{8}$ e das CFR's, ou

\footnotetext{
7 As Escolas Itinerantes são "[...] escolas localizadas em acampamentos do Movimento dos Trabalhadores Rurais Sem Terra (MST), movimento social que parte da reivindicação pelo acesso à terra, articulando-a ao projeto de transformação social”. (BAHNIUK; CAMINI, 2012, p. 331).

${ }^{8}$ Centros de Formação são espaços localizados em assentamentos ou regiões que objetivam o desenvolvimento profissional, cultural e a escolarização dos assentados e acampados. Abrigam atividades de formação diversas, no âmbito da formação técnica profissional em áreas de interesse da população das áreas de reforma agrária, como técnicos em agroecologia, técnico em saúde comunitária, os quais são devidamente legalizados ou em parcerias com outras instituições educativas, assim como desenvolve cursos voltados à formação política-ideológica.

Educação em Revista|Belo Horizonte|v.37|e229524|2021
} 
ainda em processos não formais com a atuação em Cooperativas e atividades comunitárias de caráter formativo. De acordo com os dados produzidos na presente pesquisa, constatou-se que, no início do curso, apenas sete estudantes não estavam vinculados a processos de educação formal.

A segunda turma do curso de Pedagogia para Educadores do Campo na Unioeste, a Turma Nadja Krupskaya ${ }^{9}$, ocorreu entre os anos de 2009 e 2012, no campus de Cascavel. Contudo, embora essa segunda turma tenha ocorrido nesse período, sua gestação ocorreu ainda nos marcos da realização da primeira turma. A partir da avaliação dos resultados em exercício com a primeira turma e a própria necessidade social de formação de educadores do campo, os Movimentos Sociais Populares do Campo e docentes do curso iniciaram, em 2005, a luta pela abertura da segunda turma do curso nas instâncias internas à Unioeste e junto ao PRONERA.

Esse processo que culminaria na realização da Turma Nadja Krupskaya foi iniciado com a mobilização do público para inscrever-se no processo de seleção do curso, com indicativo de sua realização para novembro de 2006. Entretanto, em razão da não celebração do convênio entre o PRONERA e a Unioeste, o Concurso Vestibular Específico para composição da segunda turma do curso foi postergado sem indicativos de sua realização. Esse fator levou os Movimentos Sociais Populares do Campo, por intermédio dos estudantes inscritos para o vestibular, à ocupação e à organização de um acampamento nas instalações do campus da Unioeste em Francisco Beltrão como forma de tensionar a conquista do curso. O acampamento na Universidade durou aproximadamente 45 dias, com uma série de atividades formativas e processos de negociação, resultando na conquista do vestibular divulgado por meio do edital no 110/2006-GRE, de 18 de dezembro de 2006.

Em face da morosidade de celebração do convênio, que foi assinado apenas em 31 de dezembro de 2008 e em decorrência de encaminhamentos internos à Universidade, o curso de Pedagogia para Educadores do Campo foi transferido para o campus da Unioeste em Cascavel. Assim, considerando o distanciamento de tempo entre o Concurso Vestibular Específico de 2006, realizado no campus de Francisco Beltrão e a celebração do convênio, foi realizado um novo Concurso Vestibular Específico para completar a constituição da turma. Esse segundo vestibular ocorreu em Cascavel, no dia 01 de abril de 2009, sendo divulgado pelo Edital no 030/2009-GRE, de 24 de março de 2009. Ainda em março de 2009, a Universidade recebe o primeiro repasse financeiro, oferecendo condições para o início da primeira etapa da sua segunda turma do curso de Pedagogia para Educadores do Campo. Analisando o perfil do público que acessou e constituiu a segunda Turma de Pedagogia da Terra na Unioeste, identificada pelos próprios estudantes como Turma Nadja Krupskaya, verifica-se uma faixa etária juvenil, que compreende idades de 18 a 38 anos. Vale destacar que em 2009, um percentual de $20 \%$ da turma possuía 18 anos. A Turma egressa foi constituída por 24 mulheres e onze homens, vindos de 25 municípios, sendo 23 municípios paranaenses e dois catarinenses. Em relação às Comunidades e aos Movimentos Sociais de vinculação dos estudantes, a Turma Nadja Krupskaya constituiu-se com sujeitos do MST e do Movimento de Mulheres Camponesas (MMC) e de distintos contextos do campo, sendo dezenove de Assentamentos da Reforma Agrária, um de Reassentamento de Comunidade Atingida por Barragens, um de Comunidade Tradicional e quatorze de Acampamentos de luta pela terra.

Um dado impactante acerca do perfil dos estudantes que integraram a Turma Nadja Krupskaya foi constado a partir da análise do Memorial de Vida que compôs o Concurso Vestibular Específico para seleção dos estudantes. De acordo com os dados sistematizados a partir dos Memoriais de Vida, constata-se a ampla negação no acesso à Educação Superior aos povos trabalhadores do campo, sendo que $85 \%$ dos egressos da Turma Nadja Krupskaya foram os primeiros de suas famílias a acessarem a Educação Superior.

No desenrolar do curso, até o ano de 2010, foram registradas quinze desistências ocasionadas por diferentes fatores que envolvem questões familiares, o acesso e a própria permanência nas etapas, mesmo com todas as possibilidades proporcionadas pelo regime de alternância.

\footnotetext{
${ }^{9}$ Nadja Krupskaya (1869 - 1939). Educadora e líder da Revolução Russa de 1917. Integrou o Comissariado do Povo para a Educação, no processo revolucionário soviético. Foi homenageada como nome de turma pela segunda turma do curso de Pedagogia para Educadores do Campo na Unioeste.

Educação em Revista|Belo Horizonte|v.37|e229524|2021
} 
No que tange à inserção dos estudantes, a partir da pesquisa realizada, constatou-se que até 2010, dos 35 estudantes da Turma Nadja Krupskaya, treze estudantes não haviam constituído nenhuma forma de inserção e atuação profissional no ambiente escolar, sendo que oito destes contribuíam em processos formativos não formais na Comunidade ou Movimento Social de vinculação. Deste modo, o perfil de atuação dos estudantes em 2010 pode ser caraterizado da seguinte forma: cinco atuavam como educadores da Educação de Jovens e Adultos; quatorze atuavam como educadores das Escolas Itinerantes; dois atuavam em Ciranda Infantil ${ }^{10}$; dois atuavam na Equipe Pedagógica do Centro de Formação em Agroecologia; três contribuíam na organização do Grupo de Jovens de suas Comunidades; cinco atuavam no Setor de Educação e Formação de seu respectivo Movimento Social; e quatro não possuíam vínculo ou inserção sistemática com nenhuma atividade formativa.

A inserção no curso, em consonância com a intencionalidade formativa proposta, que foi sendo instaurada na conexão recíproca entre tempo universidade e tempo comunidade, permitiu nos dois últimos anos do curso a efetivação de experiências e inserção dos estudantes que integravam a Turma Nadja Krupskaya em atividades educativas. Essa intencionalidade proposta pelo curso, ancorada nas necessidades de sua Comunidade de origem ou de outras Comunidades no Campo, permitiu que os estudantes em formação delineassem uma atuação profissional inicial enquanto pedagogas e pedagogos, principalmente, em processos educativos voltados à Educação Infantil, à Educação de Jovens e Adultos ou em Escolas do Campo em áreas de Reforma Agrária, essencialmente nas Escolas Itinerantes.

A terceira turma do curso de Pedagogia para Educadores do Campo na Unioeste, a Turma Anatolli Lunachaski ${ }^{11}$, ocorreu entre os anos de 2013 e 2017, no campus de Cascavel. A implementação dessa terceira turma do curso de Pedagogia da Terra na Universidade, no âmbito do PRONERA, foi aprovada pela Resolução no 201/2012-CEPE, de 29 de novembro de 2012. O vestibular para ingresso no curso, com a abertura de cinquenta vagas, teve seu resultado publicado em 18 de abril de 2013 pelo edital n ${ }^{\circ}$ 043/2013-COGEPS. Dos 118 candidatos inscritos para o Concurso Vestibular Específico para constituição da terceira turma, compareceram no dia de realização das provas 49 candidatos.

O PPP para efetivação da terceira turma - Turma Anatolli Lunachaski - (UNIOESTE, 2013), firmado na experiência com as duas turmas anteriores - Turma Antonio Gramsci e Turma Nadja Krupskaya - foi aprovado pela Resolução no 115/2013-CEPE, de 23 de maio de 2013. O curso foi integralizado em quatro anos com uma carga horária total de 3.464 horas, efetivadas em turno integral, em regime de alternância em oito etapas, na modalidade presencial. O início do curso ocorreu em 06 de junho de 2013, contando com 48 estudantes matriculados, sendo quarenta mulheres e oito homens. Assim como a Turma Nadja Krupskaya, essa terceira turma de Pedagogia da Terra na Unioeste ocorreu no campus de Cascavel. A novidade nessa nova turma foi construir as condições de alojamento dentro do próprio campus da Unioeste. Durante os quatro anos, a Turma Anatolli Lunachaski contou com o alojamento alocado junto ao Centro de Convivência dos Funcionários da Unioeste - Cascavel, em anexo à quadra de esportes do campus.

Outra peculiaridade pertinente à Turma Anatolli Lunachaski foi que sua constituição, além de considerar a seleção por meio do Concurso Vestibular Específico, contou ainda com a inserção de estudantes via Sistema de Seleção Unificada (SISU), sendo que, dos 48 estudantes que integraram a turma, doze estudantes tiveram sua inserção viabilizada por meio do SISU. Ainda como particularidade relacionada à efetivação da turma, colocou-se o processo de gestão financeira do curso, na terceira turma, os recursos repassados pelo PRONERA para o custeio de deslocamento, estadia e alimentação durante os períodos de tempo universidade, foram viabilizados por meio de bolsas aos estudantes. Isso exigiu um maior comprometimento dos estudantes na gestão coletiva do curso, do contrário muitos seriam prejudicados, caso cada estudante utilizasse os valores oriundos das bolsas de maneira individual, por exemplo. Durante três anos a turma contratou a alimentação em restaurantes próximos à Unioeste. E no

\footnotetext{
10 "Ciranda Infantil é um espaço educativo da infância Sem Terra, organizado pelo Movimento dos Trabalhadores Rurais Sem Terra (MST) e mantidos por cooperativas, centros de formação e pelo próprio MST, em seus assentamentos e acampamentos” (ROSSETTO; SILVA, 2012, p. 127).

11 Anatolli Lunachaski (1875 - 1933). Dramaturgo, crítico literário e líder da Revolução Russa de 1917. Integrou o Comissariado do Povo para a Educação, no processo revolucionário soviético. Foi homenageado como nome de turma pela terceira turma do curso de Pedagogia para Educadores do Campo na Unioeste.

Educação em Revista|Belo Horizonte|v.37|e229524|2021
} 
último ano de curso, com a implementação do Restaurante Universitário no campus de Cascavel, passou a fazer as refeições subsidiadas pela política efetivada pela Universidade, com a estruturação e o funcionamento do Restaurante Universitário, que contemplou todos os estudantes do campus.

Os estudantes que constituíram a Turma Anatolli Lunachaski mantinham vínculos com os seguintes Movimentos Sociais: MST, MMC, Pastoral da Juventude Rural (PJR), Movimento de Libertação dos Sem Terra (MLST) e Movimento Nacional de Luta pela Moradia (MNLM). Desse modo, os sujeitos que ingressaram no curso não o fizeram unicamente como indivíduos no processo formativo, mas trouxeram consigo uma história de luta seja por terra, educação, saúde, moradia, ou outras bandeiras de luta dos Movimentos Sociais. A origem desses estudantes também é diversa, 44 deles residiam no Paraná, um estudante vinha do estado de São Paulo, um estudante do estado de Santa Catarina e dois estudantes do estado do Espírito Santo.

Com base na análise de dados referentes ao perfil dos estudantes no início do curso, tem-se o panorama que expressa que dos 48 estudantes cursistas no momento inicial, um total de 26 estudantes estavam vinculados a Acampamentos de luta pela terra e a Assentamentos de Reforma Agrária organizados pelo MST. Ao longo do curso ocorreram 27 desistências que assim como nas demais Turmas estiveram ancoradas no desinteresse com a área de atuação, em problemas pessoais de cunho familiar ou econômico, bem como nas dificuldades de acesso e permanência nas etapas, elementos esses que impossibilitaram a conclusão do curso. Dos 21 estudantes egressos, somam-se dezoito mulheres e três homens, pertencentes originalmente a dezesseis Comunidades do Campo, localizadas em quatro estados diferentes, pois uma estudante mudou-se para o estado do Mato Grosso do Sul no decorrer do curso. Do conjunto da turma egressa, onze eram pessoas residentes em Assentamento da Reforma Agrária, oito em Acampamentos de luta pela terra, uma pessoa Reassentada em Comunidade Atingida por Barragem e uma pessoa não foi possível identificar o local de residência, mas possuía vínculo com uma Casa Família Agrícola. Ao ter por referência esse panorama, destaca-se mais uma vez a interface Educação Superior e Educação do Campo, configurada na relação Universidade, Movimentos Sociais Populares do Campo e PRONERA como elemento fundante na inserção dos setores populares na Universidade pública e no delineamento de uma política pública de Educação do Campo que atenda as históricas reivindicações dos povos trabalhadores do campo.

O curso de Licenciatura em Educação do Campo que possibilitou a formação de uma turma na Unioeste foi realizado entre os anos de 2010 e 2014. Esse foi o segundo curso de graduação específico para formação de educadores do campo ofertado pela Universidade. De acordo com o PPP do curso (UNIOESTE, 2008), a formação propiciada pela Licenciatura em Educação do Campo na Unioeste objetivou formar educadores para atuarem nos anos finais do Ensino Fundamental e no Ensino Médio, habilitando-os nas áreas de conhecimento das Ciências Agrárias e das Ciências da Natureza e Matemática. Essa turma do curso de Licenciatura em Educação do Campo foi identificada pelos estudantes que a constituíram como Turma Paulo Freire ${ }^{12}$.

O curso de Licenciatura em Educação do Campo na Unioeste efetivou-se a partir do edital $\mathrm{n}^{\mathrm{o}} 2$, de 23 de abril de 2008, que teve por objetivo selecionar projetos de Instituições Públicas de Educação Superior para o PROCAMPO. A proposta apresentada pela Unioeste, que teve por objetivo ofertar trinta vagas para habilitação na área do conhecimento de Ciências da Natureza e Matemática e trinta vagas para a área de Ciências Agrárias, conforme condições dipostas pelo edital do PROCAMPO, teve sua aprovação divulgada pelo edital $\mathrm{n}^{\circ} 3$, de 6 de outubro de 2008. A parceria entre o MEC e a Unioeste, que viabilizou o repasse de recursos para a realização do curso, se deu pelo Convênio ${ }^{\circ}$ $742005 / 2008$, de 31 de dezembro de 2008. Todavia, consideradas as dificuldades burocráticas relacionadas ao repasse dos recursos financeiros, não foi possível iniciar o curso no ano de 2008.

Em 2009, concomitantemente à busca pela garantia dos recursos financeiros junto ao MEC, a Unioeste juntamente com os Movimentos Sociais Populares do Campo reivindicaram junto ao Governo do Paraná a autorização para o funcionamento do curso. Conquista essa efetivada com o

\footnotetext{
12 Paulo Freire (1921 - 1997). Educador, pedagogo e filósofo brasileiro. Patrono da educação brasileira. Foi homenageado como nome de turma no curso de Licenciatura em Educação do Campo na Unioeste.

Educação em Revista|Belo Horizonte|v.37|e229524|2021
} 
Decreto $n^{\circ}$ 6.357, de 26 de fevereiro de 2010, por meio do qual o Governador do Paraná autorizou o início do curso.

Assim como no curso de Pedagogia para Educadores do Campo, a seleção para composição da turma do curso de Licenciatura em Educação do Campo na Unioeste contou com a realização de um Concurso Vestibular Específico, com provas em duas dimensões. Uma primeira voltada para a análise e a comprovação dos conhecimentos gerais dos candidatos e a segunda que considerou a elaboração de uma redação. A realização das provas ocorreu no dia 21 de março de 2010. A prova era objetiva de múltipla escolha. As questões foram voltadas para os conteúdos do Ensino Médio, considerando os conteúdos de Biologia, Física, Geografia, História, Língua Espanhola, Química, Língua Portuguesa e Matemática. A elaboração da redação consistiu na produção de um Memorial de Vida voltado para a relação com a Educação do Campo e considerando a organização e estrutura do texto e a utilização correta dos recursos ortográficos e gramaticais.

Considerando os processos que a Unioeste já vinha efetivando com o curso de Pedagogia para Educadores do Campo, para a inscrição no Concurso Vestibular Específico para o curso de Licenciatura em Educação do Campo os candidatos tiveram que apresentar a Carta de Indicação para inserção no curso. O Concurso Vestibular Específico para o curso de Licenciatura em Educação do Campo na Unioeste teve 159 candidatos inscritos, sendo 45 candidatos para a habilitação na área de Ciências Agrárias e 114 candidatos para a habilitação na área de Ciências da Natureza e Matemática.

De acordo com o resultado do Concurso Vestibular Específico divulgado pelo edital $n^{\circ}$ 074/2010-GRE de 5 de abril de 2010 para o curso de Licenciatura em Educação do Campo na Unioeste, os estudantes da Turma Paulo Freire, em sua grande maioria, de alguma forma já tinham vínculo com atividades educativas em espaços formais ou não formais. A Turma Paulo Freire inicialmente foi constituída por sessenta estudantes, destes 46 finalizaram o curso, sendo 29 mulheres e 17 homens. Esses sujeitos, formados no curso de Licenciatura em Educação do Campo na Unioeste, em sua totalidade, mantinham vínculos com 36 Comunidades do Campo, situadas em 29 municípios de cinco estados brasileiros, sendo 31 estudantes do Paraná, sete do Espírito Santo, quatro do Mato Grosso do Sul, dois de Santa Catarina e dois do Tocantins.

$\mathrm{Na}$ Turma Paulo Freire foi registrada a participação de estudantes vinculados a sete Movimentos Sociais. Dos estudantes que iniciaram o curso, 32 tinham vínculos com o MST, seis com a PJR, uma com o MNLM, dois com o MAB, dois com o MMC, dois com o MLST e uma estudante era vinculada ao Movimento dos Pequenos Agricultores (MPA).

Dos 46 estudantes que finalizaram a formação no curso na Unioeste, obtendo o grau de licenciado em Educação do Campo, 26 foram licenciados na área das Ciências Agrárias e vinte na área das Ciências da Natureza e Matemática. Em relação aos estudantes que não concluíram o curso por diferentes motivos, foram sete mulheres e sete homens. Onze mantinham vínculo com o MST e três com o MNLM. O índice maior de não conclusão do curso foi dos estudantes da área de conhecimento das Ciências da Natureza e Matemática.

De acordo com Verdério (2018), a não aderência à área de conhecimento de habilitação, atrelada às necessidades de permanência, sobretudo nos períodos de tempo universidade, junto ao frágil nível de vinculação dos desistentes com os Movimentos Sociais, bem como a debilidade na inserção em práticas educativas desenvolvidas em Comunidades do Campo colocaram-se como questões primeiras e determinantes para a não conclusão do curso.

Conforme Quadro 1, ao considerar a realização dos cursos de graduação em regime de alternância para formação de educadores do campo, verifica-se uma relação direta entre as experiências analisadas e o processo de constituição e afirmação da política pública de Educação do Campo, sobretudo, a efetividade do PRONERA e do PROCAMPO na inserção e na permanência dos povos trabalhadores do campo na Educação Superior, que por sua vez, é respaldada na interface desta com a Educação do Campo.

Quadro 1: Egressos cursos de graduação em alternância Paraná 2004 - 2019

\begin{tabular}{|c|c|c|c|c|}
\hline \multirow{2}{*}{ Universidade } & Período & Curso & $\begin{array}{c}\text { Nome da } \\
\text { Turma }\end{array}$ & $\begin{array}{c}\text { Número de } \\
\text { Egressos }\end{array}$ \\
\hline
\end{tabular}

Educação em Revista|Belo Horizonte|v.37|e229524|2021 


\begin{tabular}{|c|c|c|c|c|}
\hline \multirow{4}{*}{ UNIOESTE } & $2004-2008$ & Pedagogia para Educadores do Campo & $\begin{array}{l}\text { Turma Antonio } \\
\text { Gramsci }\end{array}$ & 35 \\
\hline & $2009-2012$ & Pedagogia para Educadores do Campo & $\begin{array}{l}\text { Turma Nadja } \\
\text { Krupskaia }\end{array}$ & 35 \\
\hline & $2010-2014$ & $\begin{array}{c}\text { Licenciatura em Educação do Campo: } \\
\text { Ciências da Natureza, Matemática e } \\
\text { Ciências Agrárias }\end{array}$ & $\begin{array}{l}\text { Turma Paulo } \\
\text { Freire }\end{array}$ & 46 \\
\hline & $2013-2017$ & Pedagogia para Educadores do Campo & $\begin{array}{l}\text { Turma Anatoli } \\
\text { Lunachaski }\end{array}$ & 21 \\
\hline UNICENTRO & $2009-2013$ & $\begin{array}{c}\text { Licenciatura em Educação do Campo: } \\
\text { Ciências da Natureza, Matemática e Ciências } \\
\text { Agrárias }\end{array}$ & $\begin{array}{l}\text { Turma Campo } \\
\text { em Movimento }\end{array}$ & 34 \\
\hline UEM & $2013-2017$ & Pedagogia para Educadores do Campo & $\begin{array}{l}\text { Turma Iraci } \\
\text { Salete Strozak }\end{array}$ & 22 \\
\hline UTFPR & $2009-2014$ & $\begin{array}{c}\text { Licenciatura em Educação do Campo: } \\
\text { Ciências da Natureza, Matemática e Ciências } \\
\text { Agrárias }\end{array}$ & $\ldots$ & 22 \\
\hline \multirow{2}{*}{ UFFS } & $2012-2017$ & $\begin{array}{l}\text { Licenciatura em Educação do Campo: } \\
\text { Ciências Sociais e Humanas }\end{array}$ & $\begin{array}{l}\text { Turma Paulo } \\
\text { Freire }\end{array}$ & 19 \\
\hline & $2014-2018$ & $\begin{array}{l}\text { Licenciatura em Educação do Campo: } \\
\text { Ciências Sociais e Humanas }\end{array}$ & $\begin{array}{l}\text { Turma Ângelo } \\
\text { Kretã }\end{array}$ & 10 \\
\hline \multirow{2}{*}{ UFPR } & $2014-2018$ & $\begin{array}{l}\text { Licenciatura em Educação do Campo: } \\
\text { Ciências da Natureza }\end{array}$ & $\begin{array}{l}\text { Turma Albert } \\
\text { Einstein }\end{array}$ & 19 \\
\hline & $2014-2018$ & $\begin{array}{l}\text { Licenciatura em Educação do Campo: } \\
\text { Ciências da Natureza }\end{array}$ & $\begin{array}{l}\text { Turma Flor do } \\
\text { Vale }\end{array}$ & 33 \\
\hline & & Total & 10 & 296 \\
\hline
\end{tabular}

FONTE: Organização dos autores (2019).

A Unioeste, como Universidade pública pioneira e protagonista junto com os Movimentos Sociais Populares do Campo no estado do Paraná na oferta de cursos de graduação em regime de alternância, coloca-se também como espaço fecundo na formação de educadores do campo. Isso fica expresso no Quadro 1, pois dos 296 egressos dos cursos de graduação para a formação de educadores do campo organizados em regime de alternância concluídos no Paraná até o ano de 2019, 137 estudantes tiveram sua formação propiciada pelos cursos na Unioeste. Ou seja, o percentual de educadores do campo egressos dos cursos de Educação do Campo da Unioeste em relação ao total de egressos nos cursos realizados no Paraná é superior a 46\%.

Considerando os elementos que deram sustentação e os resultados da experiência na Unioeste relacionados à formação de educadores do campo é possível afirmar a efetividade das ações desencadeadas no contexto da luta pela Educação do Campo no Brasil. Deste modo, a interface Educação Superior e Educação do Campo, potencializada por meio do PRONERA e do PROCAMPO, tem produzido importantes conquistas no que tange ao acesso e à permanência das classes populares nas Universidades públicas brasileiras. Isso é traduzido na experiência realizada na Unioeste que, entre 2004 e 2017, viabilizou a inserção, a permanência e a conclusão dos processos formativos na graduação a 137 sujeitos organicamente vinculados aos povos trabalhadores do campo e às práticas educativas que lhes dizem respeito.

\section{A PRODUÇÃO ACADÊMICO-CIENTÍFICA DOS ESTUDANTES NOS CURSOS EM ALTERNÂNCIA NA UNIOESTE NA INTERFACE EDUCAÇÃO SUPERIOR E EDUCAÇÃO DO CAMPO}

Considerando o perfil dos 137 egressos dos cursos de graduação para formação de educadores do campo em alternância efetivados na Unioeste, tendo especial atenção às suas vinculações com as Comunidades e com os Movimentos Sociais, e a partir da análise dos Trabalhos de Conclusão de 
Curso, conforme síntese apresentada no Quadro 2, identifica-se que as monografias elaboradas pelos 137 egressos dos cursos de formação de educadores do campo em alternância na Unioeste perpassaram questões relacionadas a dois grandes grupos temáticos: 1) Práticas Educativas Formais - Escola e Educação do Campo e 2) Práticas Educativas Não-Formais - Movimentos Sociais e Educação do Campo. Dada a diversidade de temas abordados e a abrangência dos estudos que sustentaram a elaboração das monografias analisadas, os dois grupos temáticos agregadores foram desdobrados em 32 subgrupos temáticos.

Quadro 2: Temáticas das monografias elaboradas nos cursos de formação de educadores do campo na Unioeste $2004-2017$

\begin{tabular}{|c|c|c|c|c|c|c|}
\hline $\begin{array}{l}\text { Grupos } \\
\text { Temáticos }\end{array}$ & Subgrupo Temático & $\begin{array}{c}\text { Turma } \\
\text { Antonio } \\
\text { Gramsci }\end{array}$ & $\begin{array}{l}\text { Turma } \\
\text { Nadja } \\
\text { Krupskaia }\end{array}$ & $\begin{array}{l}\text { Turma } \\
\text { Paulo } \\
\text { Freire }\end{array}$ & $\begin{array}{c}\text { Turma } \\
\text { Anatolli } \\
\text { Lunachaski }\end{array}$ & $\begin{array}{l}\text { Total de } \\
\text { TCC }\end{array}$ \\
\hline \multirow{23}{*}{ 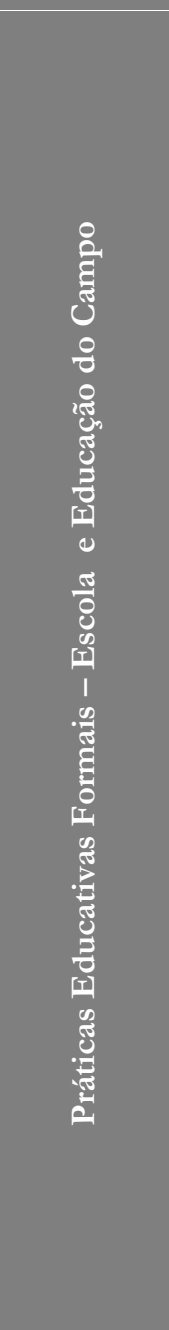 } & $\begin{array}{l}\text { Gestão escolar e a relação com a } \\
\text { comunidade }\end{array}$ & 1 & 4 & 1 & 0 & 6 \\
\hline & Metodologias e didática & 1 & 1 & 0 & 0 & 2 \\
\hline & $\begin{array}{l}\text { Organização curricular e forma } \\
\text { escolar }\end{array}$ & 1 & 2 & 2 & 1 & 6 \\
\hline & $\begin{array}{l}\text { Trabalho como princípio } \\
\text { educativo }\end{array}$ & 0 & 2 & 3 & 1 & 6 \\
\hline & $\begin{array}{l}\text { Educação especial, deficiência e } \\
\text { inclusão }\end{array}$ & 0 & 2 & 1 & 1 & 4 \\
\hline & Avaliação & 1 & 2 & 0 & 1 & 4 \\
\hline & Função social da escola & 3 & 1 & 1 & 0 & 5 \\
\hline & Juventude e escola & 0 & 0 & 2 & 0 & 2 \\
\hline & $\begin{array}{l}\text { Política educacional e práticas e } \\
\text { escolares do campo }\end{array}$ & 9 & 1 & 5 & 0 & 16 \\
\hline & Alfabetização & 1 & 2 & 0 & 1 & 4 \\
\hline & Leitura & 1 & 2 & 0 & 0 & 3 \\
\hline & Educação Infantil & 0 & 0 & 0 & 3 & 3 \\
\hline & Educação de Jovens e Adultos & 2 & 2 & 1 & 1 & 6 \\
\hline & Educação matemática & 0 & 1 & 2 & 0 & 3 \\
\hline & Gênero e escola & 1 & 1 & 1 & 2 & 5 \\
\hline & Pedagogia da Alternância & 1 & 0 & 1 & 1 & 3 \\
\hline & Educação Integral & 0 & 0 & 1 & 0 & 1 \\
\hline & Formação de educadores & 3 & 0 & 4 & 2 & 9 \\
\hline & Evasão escolar & 0 & 0 & 0 & 1 & 1 \\
\hline & Pedagogia Socialista & 1 & 0 & 0 & 1 & 2 \\
\hline & Escola Multisseriada & 0 & 0 & 0 & 1 & 1 \\
\hline & Empresariamento da educação & 1 & 0 & 0 & 0 & 1 \\
\hline & Subtotais & 27 & 24 & 25 & 17 & 93 \\
\hline \multirow{8}{*}{ 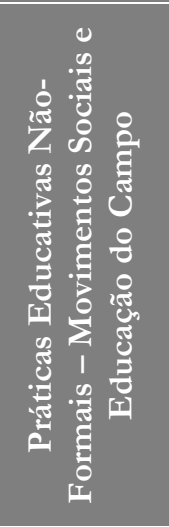 } & Debate conceitual & 1 & 0 & 3 & 0 & 4 \\
\hline & Centro de Formação & 1 & 0 & 0 & 1 & 2 \\
\hline & Formação tecnológica e técnica & 1 & 0 & 0 & 0 & 1 \\
\hline & $\begin{array}{l}\text { Questão Agrária, Comunidade } \\
\text { Camponesa e Organização }\end{array}$ & 1 & 1 & 13 & 1 & 16 \\
\hline & Produção Agrícola & 0 & 0 & 1 & 0 & 1 \\
\hline & $\begin{array}{l}\text { Juventude do Campo e } \\
\text { Movimentos Sociais }\end{array}$ & 1 & 2 & 2 & 1 & 6 \\
\hline & $\begin{array}{l}\text { Educação Infantil e Ciranda } \\
\text { Infantil }\end{array}$ & 1 & 5 & 0 & 0 & 6 \\
\hline & $\begin{array}{l}\text { Trabalho como princípio } \\
\text { educativo }\end{array}$ & 2 & 0 & 0 & 0 & 2 \\
\hline
\end{tabular}




\begin{tabular}{|r|c|c|c|c|c|}
\hline Articulação regional & 0 & 0 & 1 & 0 & $\mathbf{1}$ \\
\hline $\begin{array}{r}\text { Trabalho, Gênero e violência } \\
\text { contra a mulher no campo }\end{array}$ & 0 & 3 & 1 & 1 & $\mathbf{5}$ \\
\hline Subtotais & 8 & 11 & 21 & 4 & 44 \\
\hline Total de Monografias & 35 & 35 & 46 & 21 & 137 \\
\hline
\end{tabular}

FONTE: Organização dos autores (2019).

Em consonância com a distribuição das monografias nos dois grupos e nos 32 subgrupos temáticos elencados no Quadro 2, constata-se grande aderência de estudos orientados para as Práticas Educativas Formais - Escola e Educação do Campo ou, em outras palavras, sobre a questão da educação escolar propriamente dita. O número de trabalhos nesse grupo totalizou a produção de 93 monografias nas quatro turmas. Por sua vez, os estudos voltados para as Práticas Educativas Não-Formais Movimentos Sociais e Educação do Campo, mesmo que em índice menor, também tiveram repercussão nas elaborações das quatro turmas, resultando um total 44 monografias elaboradas.

Quando consideradas as três turmas do curso de Pedagogia para educadores do Campo Turma Antonio Gramsci, Turma Nadja Krupskaia e Turma Anatolli Lunachaski -, ao relacionar os objetos de estudo e os espaços de inserção e atuação dos estudantes-pesquisadores verificados no momento inicial dos cursos e nos Memoriais de Vida, tendo por referências ainda as elaborações e os títulos dos Trabalhos de Conclusão de Curso, é possível constatar que dos 68 trabalhos que constituíram o Grupo Temático das Práticas Educativas Formais - Escola e Educação do Campo, 54 trabalhos expressam de maneira evidente a relação entre a origem dos estudantes-pesquisadores e os objetos de estudos escolhidos. Essa vinculação também é expressa no Grupo Temático Práticas Educativas NãoFormais - Movimentos Sociais e Educação do Campo, pois dos 23 trabalhos analisados, dezenove apresentam a relação entre a inserção dos estudantes-pesquisadores e os objetos pesquisados. Já no contexto da Licenciatura em Educação - Turma Paulo Freire, verifica-se que em dezoito dos 25 trabalhos reunidos no Grupo Temático das Práticas Educativas Formais - Escola e Educação do Campo fica evidenciada uma relação recíproca, expressa, sobretudo, na vinculação e na inserção orgânica dos estudantes-pesquisadores aos processos e aos espaços que sustentaram seus respectivos objetos de estudo. Do mesmo modo, no curso de Licenciatura em Educação do Campo, dessezete dos 21 trabalhos que se vinculam ao Grupo Temático Práticas Educativas Não-Formais - Movimentos Sociais e Educação do Campo evidenciam essa relação entre os objetos de estudo e a inserção e atuação dos estudantespesquisadores nos espaços que se constituíram como lócus e que sustentaram seus objetos de pesquisa.

Assim, verifica-se que 108 dos 137 trabalhos monográficos elaborados nos cursos de Educação do Campo ofertados na Unioeste expressam por meio do registro textual nos próprios trabalhos a relação recíproca entre a origem e a inserção dos estudantes-pesquisadores e seus objetos de estudo. A título de exemplificação dessa relação, são destacados três trabalhos monográficos que evidenciam essa relação. No caso do curso de Pedagogia para Educadores do Campo, da Turma Antonio Gramsci, destaca-se o trabalho intitulado "Práticas de leitura e escrita: um estudo na Escola Rural Municipal Herbert de Souza", no qual o autor registra de maneira contundente seu vínculo com o objeto de estudo escolhido, seja por meio da atuação na Educação de Jovens e Adultos, na Educação Infantil ou no Ensino Fundamental, voltando-se para as problemáticas relacionadas ao processo de leitura e escrita em tais contextos. Ao considerar essa sua trajetória como educador do campo, o estudantepesquisador pontua em seu trabalho monográfico que "[...] ficou claro que jamais poderia esquecê-los, pois percebi que em minha carreira de educador tais atitudes não deveriam acontecer. Então passei a agir de forma que despertasse a vontade da criança para a aprendizagem da leitura e da escrita" (MENDES, 2008, p. 6). Da Turma Nadja Krupskaya destaca-se a pesquisa intitulada "Sujeitos com deficiência: possibilidades e desafios de sua inserção no cotidiano escolar da Escola Itinerante Zumbi dos Palmares", na qual a autora registra em sua elaboração que a vivência enquanto educadora da escola pesquisada permitiu identificar a dificuldade de acesso dos estudantes com necessidades educativas especiais (RODRIGUES, 2012), sendo essa temática assumida como seu tema de pesquisa no Trabalho de 
Conclusão de Curso. Já no curso de Licenciatura em Educação do Campo, Turma Paulo Freire, destacase a elaboração "A relação trabalho e educação na prática pedagogica do CEFFA do Bley" na qual o estudante-pesquisador registra que seu vínculo com a realidade pesquisada "[...] possibilitou uma relação para além de uma formalidade contratual, mas proporcionando uma relação também militante, comprometida em contribuir na construção dessa experiência." (FAVERO, 2014, p. 8).

Nesse sentido, é crível a compreensão de que as temáticas pesquisadas nos cursos de Educação do Campo efetivados na Unioeste por meio do PRONERA e do PROCAMPO mantiveram conexões com problemas concretos vivenciados nas Comunidades de inserção dos estudantes. Esse dado evidencia a contribuição dos cursos de formação de educadores do campo realizados na Unioeste na perspectiva de avanço da educação dos povos trabalhadores do campo, culminando com a formação de profissionais com compromisso político e competência técnica, com condições de aportarem junto às suas Comunidades uma atuação profissional no sentido da promoção e da qualificação dos processos educativos desencadeados.

Deste modo, considerando os processos de pesquisa desencadeados pelos estudantes dos cursos de Pedagogia da Terra e de Licenciatura em Educação do Campo na Unioeste e os resultados das monografias analisadas, destaca-se ainda o orgânico vínculo dos objetos pesquisados com os desafios existentes para avançar no trabalho educativo nas Comunidades do Campo. Esse elemento coloca-se como um diferencial produzido coletivamente na formação docente do educador do campo, resgatando e afirmando o compromisso social do sujeito pesquisador e do processo de pesquisa, na medida em que oferece um retorno socialmente referenciado para a vida da Comunidade.

\section{CONSIDERAÇÕES FINAIS}

Os cursos de Pedagogia para Educadores do Campo e de Licenciatura em Educação do Campo na Unioeste, ao dar materialidade à interface Educação Superior e Educação do Campo, por meio da inclusão e da permanência dos povos trabalhadores do campo em cursos de graduação organizados com essa intencionalidade, trazem para ambiente interno à Universidade e à produção acadêmico-científica temas de pesquisa que expressam sua relevância tanto para os estudantes em formação, como também para as Comunidades e Movimentos Sociais Populares do Campo. Isso se torna evidente, pois as problemáticas de pesquisa são geradas e refletem questões postas na realidade de inserção e atuação dos estudantes-pesquisadores que, antes mesmo de adentrarem o curso de graduação, constituem-se como educadores do campo, seja em espaços formais ou não-formais de educação imersos na realidade do campo.

Assim, considerar a interface Educação Superior e Educação do Campo nos cursos de formação de educadores do campo em alternância implica conectar-se a materialidade de origem dos sujeitos da luta pela Educação do Campo considerando os avanços, os desafios e as implicações que isso gesta no interior da Universidade pública. A inclusão e a permanência das classes populares na Educação Superior em sua interface com a Educação do Campo carregam consigo a potencialidade de problematizar, sistematizar e compreender a realidade, na perspectiva de ampliação do acesso ao conhecimento, e ao mesmo tempo, indaga sobre o papel social da Universidade, na medida em que esta é tensionada a oferecer um retorno socialmente qualificado frente às contradições e às mazelas que afligem a existência dos povos trabalhadores do campo, com destaque para o seu direito à educação em todos os níveis.

Desse modo, os cursos de graduação em alternância realizados por meio do PRONERA e do PROCAMPO contribuem para imprimir uma ressignificação da função social da Universidade atrelada a um caráter popular e de democratização da Educação Superior em três dimensões complementares: o acesso (MARTINS, 2012), o conteúdo e a forma (FRIGOTTO, 2011). A primeira das dimensões diz respeito ao acesso, na medida em que ampliam vagas para sujeitos da classe trabalhadora, historicamente excluídos desse nível de educação. A segunda dimensão está atrelada ao conteúdo, uma vez que, por meio da materialidade de origem dos sujeitos da luta pela terra e da Educação do Campo, são introduzidos na Universidade problematizações e temas produzidos e demandados a partir das contradições do campo brasileiro. E por último, mas não menos expressivo, a dimensão da 
forma, pois ao constituirem e afirmarem o regime de alternância enquanto possibilidade concreta de acesso e permanência dos povos trabalhadores do campo na Universidade, produzem uma organização curricular sustentadora de processos formativos articulados em dois tempos-espaços que se entrelaçam, sejam eles a própria Comunidade do Campo de inserção e a Universidade, essa última, como espaço que passa a ser ocupado de maneira intencional e coletiva por aqueles sujeitos que se produzem coletivamente em suas organizações e na luta de classes, os povos trabalhadores do campo.

\section{REFERÊNCIAS}

ANDRADE, M. R.; DI PIERRO, M. C. A construção de uma política de Educação na Reforma Agrária. In: ANDRADE, M. R. et al. (Org.). A Educação na Reforma Agrária em Perspectiva: uma avaliação do Programa Nacional de Educação na Reforma Agrária. São Paulo: Ação Educativa; Brasília: PRONERA, 2004. p. 19-35.

APEC - ARTICULAÇÃO PARANAENSE POR UMA EDUCAÇÃO DO CAMPO. Carta de Porto Barreiro. II Conferência Estadual por uma Educação Básica do Campo, Porto Barreiro/PR, 2 a 5 de novembro de 2000. In: MANCHOPE, E. C. P.; LISBOA, E.; HENRIQUES, M. J. R. (Orgs.) Articulação Paranaense: "Por uma Educação do Campo". Temáticas abordadas na II Conferência Estadual. Porto Barreiro: APEC, 2000. (Caderno 2, Articulação Paranaense por uma Educação do Campo).

BAHNIUK, C.; CAMINI, I. Escola Itinerante. In: CALDART, R. S. et al. (orgs.). Dicionário da Educação do Campo. Rio de Janeiro, São Paulo: EPSJV, Expressão Popular, 2012. p. 331-336.

BRASIL. Ministério da Educação. Secretaria de Educação Continuada, Alfabetização e Diversidade. Edital $\mathrm{n}^{\circ}$ 2, de 23 de abril de 2008. 2008. Disponível em: http://portal.mec.gov.br/arquivos/pdf/edital procampo.pdf. Acesso em: 12 jan. 2018.

BRASIL. Ministério da Educação. Conheça as Universidades participantes do PROCAMPO 2010. 2010. Disponível

em:

http:/ / portal.mec.gov.br/index.php?option $=$ com docman\&view=download\&alias=6463-procampo2010-tabela\&category slug=agosto-2010-pdf\&Itemid=30192.

Acesso em: 12 jan. 2018.

BRASIL. Ministério do Desenvolvimento Agrário. Instituto Nacional de Colonização e Reforma Agrária. Manual de Operações do PRONERA. Aprovado pela Portaria/INCRA/P No 19, de 15.01.2016. Brasília-DF. 2016. Disponível em: http://www.incra.gov.br/sites/default/files/uploads/reformaagraria/projetos-e-programas/pronera/manual pronera - 18.01.16.pdf. Acesso em: 22 fev. 2018.

BRASIL. Ministério da Educação. Portaria $\mathbf{n}^{\circ}$ 86, de $1^{\mathbf{o}}$ de fevereiro de 2013: Programa Nacional de Educação do Campo - PRONACAMPO, 2013. Disponível em: http://pronacampo.mec.gov.br/. Acesso em: 14 set. 2017.

CAMPOS, J. C. de et al. Vozes da Educação do Campo na interface com a Unioeste - Ensino Superior: inclusão e permanências dos Setores Populares. Cascavel: TV IMAGO, 2019. (Coletânea de Vídeos). Disponível em: https://www.youtube.com/channel/UCw5WgyTakBLJwu5QGjDvLwg.

CHAUÍ, M. Escritos sobre a Universidade. São Paulo: Ed. UNESP, 2001.

FAVERO, C. A relação trabalho e educação na prática pedagogica do CEFFA do Bley. 2014. 74 f. (Trabalho de Conclusão de Curso) - Curso de Pedagogia para Educadores do Campo da Universidade Estadual do Oeste do Paraná, Francisco Beltrão, 2014. 
FRIGOTTO, G. Projeto societário contra-hegemônico e educação do campo; desafios de conteúdo, método e forma. In: MUNARIN, A. et al. (orgs). Educação do campo: reflexões e perspectivas. 2. ed. Florianópolis: Insular, 2011.

GHEDINI, M. C. et al. Formação de Educadores do Campo: interface entre a Universidade Estadual do Oeste do Paraná e os Movimentos Sociais Populares do Campo. In: LOSS, A. S.; VAIN, P. D. Ensino Superior: palavras, pesquisas e reflexões entre movimentos internacionais. Curitiba: CRV, 2018. p. 273295.

HORÁCIO, A. de S. Licenciatura em Educação do Campo e Movimentos Sociais: análise do curso da Universidade Federal de Minas Gerais. 2015. 156 f. Dissertação (Mestrado em Educação) Universidade Federal de Viçosa - UFV, Viçosa/MG, 2015.

IPEA - INSTITUTO DE PESQUISA ECONÔMICA APLICADA. II PNERA - Relatório da II Pesquisa Nacional sobre a Educação na Reforma Agrária. Brasília, DF: IPEA, 2015.

LEAL, A. A. et al. Cartografia das Licenciaturas em Educação do Campo no Brasil: expansão e institucionalização. In: MOLINA, M. C.; MARTINS, M. F. A. (orgs.). Formação de formadores: reflexões sobre as experiências da Licenciatura em Educação do Campo no Brasil. Belo Horizonte: Autêntica, 2019. p. 39-53.

LOSS, A. S. et al. (Orgs.). Ensino Superior "em movimento": aproximações da inclusão pelos princípios da educação popular. Curitiba: CRV, 2018.

LOSS, A. S.; VAIN, P. D. (Orgs.). Ensino Superior e inclusão: palavras, pesquisas e reflexões entre movimentos internacionais. Curitiba: CRV, 2018.

MARTINS, J. F. A Pedagogia da Terra: os Sujeitos do Campo e do Ensino Superior. Revista Educação, Sociedade \& Culturas, n 36,2012 . p. 103-119.

MEC - MINISTÉRIO DA EDUCAÇÃO. Secretaria de Educação Superior. Secretaria de Educação Profissional e Tecnológica. Secretaria de Educação Continuada, Alfabetização e Diversidade. Coordenação Geral de Educação do Campo. Minuta Original Licenciatura (Plena) em Educação do Campo. 2006. In: MOLINA, M. C.; SÁ, L. M. (Orgs.). Licenciaturas em Educação do Campo: registros e reflexões das experiências-piloto (UFMG; UnB; UFBA e UFS). Belo Horizonte: Autêntica, 2011. (Coleção Caminhos da Educação do Campo, 5). p. 357-364.

MENDES, E. P. Práticas de leitura e escrita: um estudo na Escola Rural Municipal Herbert de Souza. 2008. 41 f. (Trabalho de Conclusão de Curso) - Curso de Pedagogia para Educadores do Campo da Universidade Estadual do Oeste do Paraná, Francisco Beltrão, 2008.

MOLINA, M. C.; SÁ, L. M. (Orgs.). Licenciaturas em Educação do Campo: registros e reflexões a partir das experiências piloto. Belo Horizonte: Autêntica, 2011. (Coleção Caminhos da Educação do Campo, 5).

MOLINA, M. C. et al. A produção do conhecimento na licenciatura em Educação do Campo: desafios e possibilidades para o fortalecimento da educação do campo. Revista Brasileira de Educação, v. 24, 2019. Diponível em: https://www.scielo.br/pdf/rbedu/v24/1809-449X-rbedu-24-e240051.pdf. Acesso em: 20 dez. 2020.

PINTO, Á. V. A questão da Universidade. 2. ed. São Paulo: Cortez, 1994. 
RODRIGUES, E. K. Sujeitos com deficiência: possibilidades e desafios de sua inserção no cotidiano escolar da Escola itinerante Zumbi dos Palmares. 2012. 56 f. (Trabalho de Conclusão de Curso) - Curso de Pedagogia para Educadores do Campo da Universidade Estadual do Oeste do Paraná, Cascavel, 2012.

RAMOS, M. N. et al. Referências para uma política nacional de Educação do Campo. Brasília: Secretaria de Educação Média e Tecnológica, Grupo Permanente de Trabalho de Educação do Campo, 2004.

ROSSETTO, E. R. A; SILVA, F. T. de. Ciranda Infantil. In: CALDART, R. S. et al. (orgs.). Dicionário da Educação do Campo. Rio de Janeiro, São Paulo: EPSJV, Expressão Popular, 2012. p. 125-127.

SANTOS, C. A. dos (Org.). Educação do Campo e políticas públicas no Brasil: o protagonismo dos movimentos sociais do campo na instituição de políticas públicas e a Licenciatura em Educação do Campo na UnB. Brasília: Líber Livro; Faculdade de Educação/Universidade de Brasília, 2012.

UNIOESTE. Resolução n 083/2004-CEPE. Aprova o Projeto Político Pedagógico do Curso de Pedagogia para Educadores do Campo, do Centro de Ciências Humanas - Campus de Francisco Beltrão. Cascavel, PR: Universidade Estadual do Oeste do Paraná, 2004.

UNIOESTE. Resolução no 050/2009-CEPE: Projeto Político-Pedagógico do Curso Especial de Licenciatura em Educação do Campo. Cascavel, PR: Universidade Estadual do Oeste do Paraná, 2009.

UNIOESTE. Projeto Político Pedagógico do Curso de Pedagogia para Educadores do Campo. Cascavel, PR: Universidade Estadual do Oeste do Paraná, 2013.

UNIOESTE. Boletins de Dados. 2019. Disponíveis em: https://www5.unioeste.br/portalunioeste/proplanejamento/dir-de-avaliacao-institucional/divisao-deinformacao/boletin-de-dados. Acesso em: 03 out. 2019.

VERDÉRIO, A. A pesquisa em processos formativos de professores do campo: a Licenciatura em Educação do Campo na UNIOESTE (2010 - 2014). 2018. 362 f. Tese (Doutorado) - Programa de PósGraduação em Educação da Universidade Federal do Paraná, Curitiba, 2018. 